\title{
Convergências e divergências dos discursos de Heidegger e Simondon sobre a técnica moderna
}

Convergences and divergences in the discourses of Heidegger e Simondon about modern technology

\section{Ednei de Genaro}

\section{Resumo}

No artigo, localizamos as convergências e divergências dos discursos de Heidegger e Simondon sobre a técnica moderna. Expomos, para tanto, as mudanças no modo de pensar e agir que os autores propõem, dado o caráter da técnica moderna. Na esteira da problemática, eles se mostram contra a tradição filosófica que relaciona técnica/homem. Não por menos, apontamos como eles são hoje expoentes de temas capitais para estudos da tecnologia e sociedade na modernidade, tais como: a questão do humanismo; a abertura à perspectiva fenomenológica da técnica; e a compreensão cuidadosa do universo tecnológico. Conclusivamente, destacamos os divergentes saldos dos autores por meio de seus constrastantes compromissos filosóficos.

Palavras-chave: Técnica moderna; Fenomenologia; Cultura Técnica; M. Heidegger; G. Simondon

\section{Abstract}

In the article, we locate the convergences and divergences in the discourses of Heidegger and Simondon on modern technique. For that, is showed the change in the modes of thoughts and acting those authors proposes. We explain how they going to against the philosophical tradition that relates technology and human kind. Not least, it's pointed as the authors are today exponents of subjects for studies of capital and technology in modern society, such as: the question of humanism, openness to the phenomenological perspective of technique, and careful understanding of the technological universe. Conclusively, we highlight the differing balances of the authors through their contrastive philosophical commitments.

Keywords: Modern technology; Phenomenology; Culture Technique; M. Heidegger, G. Simondon

\section{Introdução}

Ainda que realizem diagnósticos diferentes, Heidegger (1980; 1991; 2000; 2001; 2005) e Simondon (1969; 1983; 1989) nos convocam a pensar a técnica de modo ontológico e, por conseguinte, sugerem novas respostas ao modo de relacionamento do homem com a técnica na modernidade, que 
ultrapassa as visões tradicionais. Nas reflexões sobre a técnica, abertas por estes autores, temos a oportunidade de ultrapassar as simples visões de tecnofobia ou tecnofilia a respeito.

No artigo, localizamos as convergências e divergências dos discursos de Heidegger e Simondon. Ao colocar seus diagnósticos sobre a técnica moderna e propor mudanças no modo de pensar e agir, ambos os autores explicitam a problemática de crise da relação destacada, dando caminhos diferentes de sua superação. Apresentam novas reflexões para entender o modo de ser da técnica e o universo tecnológico em que os seres humanos acabam se inserindo e constituindo. Criticam o tipo de humanismo que predominou na explicação da relação entre o homem e a técnica; e revelam um original e imbricado relacionamento entre a técnica e o homem.

Em síntese, com Heidegger concluiremos como o pensamento reflexivo, que almeja alcançar o 'sentido do Ser' das coisas (natureza, homem, técnica), foi obliterado na modernidade. Em uma atitude de pensar meditativo sobre a técnica moderna, o filósofo alemão nos revela o que há de originário e substancial nela. O caráter ontológico da técnica moderna será a própria demonstração do que vem a ser a modernidade, assim como, fator de crítica que nos remete a comentar por fim (e contrastar com Simondon) a questão do humanismo em sua obra.

Simondon, por sua vez, ruma em direção a uma ontologia genética em que procura alcançar o 'sentido do Devir' para a natureza, homem e técnica, de modo que veio a enfatizar uma epistemologia não-dualista para entender a fenomenologia que envolve o devir homem e máquina (isto é, a técnica moderna). O filósofo francês proporá investigar os ambientes de individuações, hibridizações e alteridades que encampam na modernidade instituindo por fim uma nova veste ao humanismo, o humanismo técnico, em que advoga a superação das problemáticas dos mútuos agenciamentos que não são observados em formas de pensar objetivante.

\section{Martin Heidegger}

Com Heidegger, inaugura-se uma nova perspectiva de interpretação ontológica para se pensar a técnica (e o homem). Com este autor compreendemos que 0 ato de pensar é um ato fenomenológico. Sua perspectiva, portanto, é de "voltar às coisas mesmas", orientando-se para os fenômenos e assim para aquilo que se revela à consciência como essênciadas-coisas-mesmas (ontologia). Heidegger medita sobre a técnica e esta meditação trouxe saldos importantes, pois expôs o caráter da técnica moderna: 1) dentro de uma dimensão ontológica, que ele chama de Gestell; 2) como um modo de desvelamento (Entborgenheit), isto é, um modo de acesso à verdade (Aletheia); 3) como uma ordem volitiva, constante e uniforme, de realização do fazer técnico que carrega o próprio destino temporal do ser humano; 4) e como uma conjectura que produz sentido e crítica à modernidade.

O entendimento de Heidegger sobre a técnica é relativamente bem conhecido e explorado ${ }^{1}$. De tal modo, nesta breve explanação, tomaremos a 
direção de enfatizar os pontos já referidos, com vista a esclarecer o tipo de relacionamento entre o ser técnico e humano na modernidade.

Desde a publicação da primeira grande obra de Heidegger - "Ser e Tempo" [1927] -, ou seja, no momento intelectual chamado de 'o primeiro Heidegger', sua investigação fenomenológica da existência humana já se voltava para entender o horizonte em que a temporalidade é crucial para entender a manifestação do ser nos tempos modernos - o objetivo central de seu trabalho. Para ele, o sentido do ser só pode ser desvendado através de sua temporalização no mundo: o ser-do-homem é um ser-no-mundo; ele está 'lançado' no mundo. O mundo é a abertura para a temporalização do ser-aí (Dasein) ${ }^{2}$. Importava captar, fundamentalmente, que o ser-do-homem não era um ente fixo, acabado, mas um ser permanentemente instável, ser definido pela sua finitude temporal no mundo, a fim de sua 'autenticidade'. 0 tempo, enquanto tal, no processo de temporalização, patenteia a abertura na qual o ser tem condições de se desvelar ou de se velar (obscurecer).

Heidegger, neste momento, propôs uma analítica existencial que ressaltou o modo de ser do homem com o modo de ser das coisas, tornando assim possível pensar a técnica (tratada na obra "Ser e Tempo" como 'coisas'; 'instrumentos') como uma manifestação objetual no mundo, mas também como um modo de conhecimento.

Rigorosamente, um instrumento nunca "é". O instrumento só pode ser o que é num todo instrumental que sempre pertence a seu ser. Em sua essência, todo instrumento é "algo para..." (...). O modo de lidar, talhado segundo o instrumento, é o único lugar em que ele pode se mostrar em seu ser como, por exemplo, o martelar com o martelo, não apreende tematicamente esse ente como uma coisa apenas ocorre, da mesma maneira que o uso não se sabe da estrutura do instrumento como tal. O martelar não somente não sabe do caráter instrumental do martelo como [também] se apropriou de tal maneira desse instrumento que uma adequação mais perfeita não seria possível (HEIDEGGER, 2005, p. 110).

$\mathrm{O}$ instrumento tem sentido apenas para aqueles que o experienciam e entendem seu universo simbólico. De tal modo, mesmo antes de explicitar sobre a ontologia da técnica no escrito "A questão da técnica" [1953], para o Heidegger de "Ser e Tempo", a temporalidade determinada pelo "mundo dos objetos' já não era vista dentro de uma simples visão instrumental. Como afere Vattimo (1995, p. 30-31):

Antes que ser simples presencias, realidades provistas de una existencia 'objetiva', las cosas son para nosotros instrumentos. La utilizabilidad (Zuhandenheit) de las cosas o en general su significado en relación con nuestra vida (amenaza, placer, indicio de algo diferente, etc., en suma, todos los modos en que las insertamos en nuestra existencia y de alguna manera las referimos a nuestros fines) no es algo que se agregue a la "objetividad" de las cosas sino que es su modo de darse más originario, el modo en que en primer lugar se presentan en nuestra experiencia (..). Las cosas son ante todo instrumentos; pero el instrumento nunca está aislado, siempre es instrumento para algo (...). Instrumento se refiere no sólo al uso específico para el cual está hecho, sino también, por ejemplo, se refiere a las personas que lo usan, al material de que está constituido, etc. Sin embargo, el instrumento como tal no está hecho para manifestar tales 
referencias; está hecho para un cierto empleo y no para suministrar todas estas informaciones varias. Hay sin embargo un tipo de entes intramundanos utilizables en los cuales el carácter de la referencia, precisamente en este sentido "informativo", no es sólo accidental, sino que es constitutivo: son los signos.

Ora, Heidegger nos mostra a conjectura em que a análise existencial do ser-no-mundo não é apenas a constatação da totalidade de instrumentos que nos permeia. Nós lidamos, empenhados, manuseamos, surpreendemos com o caráter objetual da técnica no mundo (que ele entende em sentido amplo: a roupa, televisão, caneta, martelo, o espelho, chave, luminária... a ponte, rua, sol, lua...); tornamo-nos familiarizados, isto é, damos significados, experimentando e inserindo temporalmente na 'mundanidade do mundo'. A técnica é, pois, imanente à vida humana. Ela não é passividade, mas forma ativa que influencia concreta e decisivamente a relação que o homem estabelece com o mundo. A técnica participa da fundamentação do mundo e proporciona uma temporalidade ao homem.

Em "Ser e Tempo", Heidegger salientava que a técnica constituía um universo da 'presença' do ser-no-mundo lançado num projeto (caracterizando o homem e guiando-o para uma experiência no mundo).

Todavia, a partir do texto de "A questão da técnica", o filósofo se abre para nova meditação sobre a técnica, destacando um plano crítico que o levou a entender a técnica moderna como um modo de desvelamento e uma volição que carrega o próprio destino temporal do homem e seu 'fazer' no mundo ${ }^{3}$.

Nos momentos antecedentes a esse novo pensar de Heidegger, duas influências foram marcantes: a leitura de textos de Ernst Jünger - tais como o artigo "A mobilização total" [1930] e o livro "Der Arbeiter" [O trabalhador, 1932] -, e a compreensão da obra de Nietzsche. Em seu próprio artigo "O reitorado 1933/34" [1945], Heidegger destacava o teor desses acontecimentos intelectuais. Declarava que com E. Jünger e F. Nietzsche ele ficou ciente da relação entre a noção de vontade de poder, técnica moderna e a figura do trabalhador como instâncias para o ponto de vista de 'volição total', planetária, que caracteriza o mundo moderno. Loparic (2002, p.218) nota que:

A leitura de Jünger levou Heidegger às seguintes conclusões: 1) que a sua fenomenologia da facticidade (do cotidiano) de 1927 é ainda ingênua, 2) que ela não representa um ponto de partida adequado para formular a questão do ser nos dias de hoje, 3) que a técnica moderna, pensada no horizonte da metafísica nietzschiana da vontade de poder, é o sentido do ser que prevalece, 4) que, portanto, Nietzsche é o pensador decisivo a ser consultado em qualquer tentativa de compreender e ultrapassar esse sentido do ser. Essas conclusões levaram Heidegger a constatar o fracasso do projeto de repensar o sentido de ser em termos da ontologia fundamental, exposta em Ser e tempo, e a procurar outros horizontes para essa pergunta, crise que resultou na Kehre, isto é, na introdução do conceito de acontecência do ser (Seinsgeschichte), característico da segunda fase do pensamento heideggeriano. 
Heidegger compreenderá o niilismo moderno do homo faber como 'retirada' ou 'esquecimento do ser'. O problema será entender como 'o ser subtrai-se no mesmo processo que se desoculta tecnicamente'. "A crítica da técnica moderna de Heidegger, escreve Brüseke (2001, p.57), abrange todos os aspectos que contribuem para o esquecimento do Ser como a natureza reificada e objetivada, a cultura como indústria, a política usurpadora e os ideais cobertos por construções apressadas e fugazes" 4.

Custa enfatizar que Heidegger não quer demonização ou simples rejeição da técnica. Ele quer, em primeiro lugar, captar sua essência e situar, a partir daí, o modo como o ser do homem se relaciona com esta.

$\mathrm{Na}$ modernidade, a imperante fundamentação da racionalidade da ciência está subordinada ao modo com que se apresenta a técnica moderna. O homo faber moderno acredita se justificar pela razão da ciência moderna, que trouxe o pensar 'calculante' em detrimento do pensar 'meditante' (HEIDEGGER, 2000).

$\mathrm{Na}$ "Carta sobre o humanismo" (1991), Heidegger (2001) destacou que nos atributos da ciência moderna - a busca de perfeição, previsão, controle, determinação, verdade universal e necessária - somos investidos pelo modo técnico de ver o mundo do humanismo tradicional. A técnica moderna torna-se a pré-deliberação, o pré-modelamento para o nosso modo de pensar e agir. A partir da apresentação da técnica moderna, esquecemos o ser, seus ritmos e modos próprios de viver. De tal modo, o homo faber moderno se firma por meio de um sujeito de conhecimento e da objetivação do mundo, empenhando o caráter temporal objetivado e subordinando o tempo da vida dentro de um determinado tempo do mundo como um 'processo secularizado' .

Como atestou Brüseke (2001), nossa ocupação no mundo carrega-se de um ideal apressado e fugaz, a cultura torna-se industrial e o objetivismo a toda prova. Heidegger demarcou a 'decadência' que mostra este modo de viver, pois somos subordinados aos comportamentos industriais, impróprios ao modo de ser que medita e confere sua presença autêntica no mundo autêntico, capaz de uma cotidianidade autêntica, que cuida de si e do mundo.

Pois bem, e qual é o modo de ser da técnica moderna? E que dimensão volitiva ela origina ao ser humano?

Heidegger nos mostra que o entendimento metafísico, desde a antiguidade, articulou sempre as quatro causas aristotélicas (formal, material, final e eficiente) para diagnosticar o conceito das coisas. No entanto, fechado neste jogo de causalidades, não se percebeu o 'deixar vir à presença' das coisas mesmas. Assim, para ele, o que constitui a essência das coisas - tanto nas coisas da natureza (phisis) como das coisas técnicas (tekne), devem ser compreendidas pelo modo que se dá seu produzir (poeisis), isto é, pelo modo em que se apresenta o desvelar das coisas sua verdade (HEIDEGGER, 2001).

A essência da técnica é um modo peculiar de desvelamento (Entborgenheit), isto é, de revelação da verdade (Alétheia). Ao se encontrar com a dimensão ontológica da técnica, Heidegger nos mostrou que ia além das visões instrumentais (técnica como 'meio para alcançar certos fins') e antropológicas (técnica como 'fazer do homem'). Ele nos diz: "A técnica não 
é, portanto, um simples meio. A técnica é uma forma de desencobrimento. Levando isso em conta, abre-se diante de nós todo um outro âmbito para a essência da técnica. Trata-se do âmbito do desencobrimento, isto é, da verdade" (HEIDEGGER, 2001, p. 17).

A questão problemática é que o desvelamento da técnica moderna é diferente do desvelar da técnica antiga (artesanal). Para Heidegger, a técnica antiga, especificamente a dos gregos, ainda limitava 0 desocultamento técnico (da verdade, da Alétheia) por meio da produção (poeisis), de tal forma que o fazer dos gregos ainda se restringia às artes manuais, dos artesões. Marcadamente semelhante à poesis da natureza, da semente que se torna uma árvore, a poesis da técnica emergia na construção do barco, da casa, do vaso.

Nos escritos em que Heidegger começa a notar o caráter específico da técnica moderna, ele realiza uma diferenciação crucial que não se encontrava em "Ser e Tempo". A técnica moderna exige um novo modo de relacionamento com a natureza e os homens, que se agrega aos horizontes da episteme moderna. A explicação dessa diferença pode ser ostentada com um exemplo dado pelo próprio Heidegger:

\begin{abstract}
A lavra do lavrador não desafia o lavradio. Na semeadura, apenas confiava a semente às forças do crescimento, encobrindo-a para seu desenvolvimento. Hoje em dia, uma outra posição também absorveu a lavra do campo, a saber, a posição que dis-põe da natureza. E dela dispõe, no sentido de uma exploração. A agricultura tornou-se indústria motorizada de alimentação. Dis-põe-se o ar a fornecer azoto, o solo a fornecer minério (...) (Idem, p. 20).
\end{abstract}

A técnica moderna (Gestell) nos atende a uma volição que é de caráter maquinal de 'provocação' (Herausforderung), de 'desafiar' a natureza; pois com ela tudo se torna 'estoque', 'armazenamento', 'fundo de reserva'. Heidegger resume em uma palavra este sentido da técnica moderna: tudo se torna disponibilidade (Bestand), ou seja, todas as coisas ficam em ordem volitiva regida, constante e uniforme, para a realização do fazer técnico de que o homem se satisfaz. Heidegger lança, mais uma vez, um exemplo significativo:

\begin{abstract}
A usina hidreelétrica não está instalada no Reno, como a velha ponte de madeira que, durante séculos, ligava uma margem à outra. A situação se inverteu. Agora é o rio que está instalado na usina. O rio que hoje o Reno é, a saber, fornecedor de pressão hidraúlica, o Reno o é pela essência da usina. Para se avaliar, mesmo à distância, o extraordinário aqui vigente, prestemos atenção, por alguns instantes, no contraste das duas expressões: 'o Reno' instalado na obra de engenharia da usina elétrica e 'o Reno' evocado pela obra de arte do poema de mesmo nome, 'o Reno', de Hölderin (Idem, p.20).
\end{abstract}

A partir disso, Heidegger demarca um valor diferencial do mundo moderno: a "armação" ou "com-posição" (Gestell) no mundo". Gestell é o sentido moderno da técnica e o nosso destino histórico, uma vez que a questão final da disponibilidade é pôr o próprio homem como ser dis-posto. A técnica moderna não é apenas o ato humano (não é apenas pelo homem que as coisas ficam dis-postas); mas sim o próprio homem se encontra 
imerso na volição incondicional da técnica moderna ${ }^{7}$. Eis o 'perigo máximo', pois quando o 'esquecimento do ser' avança, mais é retirada a liberdade humana frente à armação tecnológica. $\mathrm{O}$ homem, neste estado sistêmico e essencial da técnica, torna-se também 'fundo de reserva', 'coisificado', 'objetivado'. Como conclui HEIDEGGER (Idem, p. 38), "a com-posição é o perigo extremo porque justamente ela ameaça trancar o homem na disposição, como pretensamente o único modo de descobrimento" (p. 35) .

O triunfo do equipamento e o mundo sob o controle técnico-científico foram preocupações que continuaram na obra heideggeriana. Em "O fim da filosofia e a tarefa do pensamento" [1966], Heidegger mostrava quanto o horizonte cibernético colocava transformações profundas na sociedade (e levava a necessidade de mudança na forma do pensar):

Não é necessário ser profeta para reconhecer que as modernas ciências que estão se instalando serão, em breve, determinadas e dirigidas pela nova ciência básica que se chama cibernética. (...) O caráter desta cientificidade é de natureza cibernética, quer dizer, técnica. Provalvelmente desaparecerá a necessidade de questionar a técnica moderna, na mesma medida em que mais decisivamente a técnica marcar e orientar todas as manifestações no Planeta e o posto que o homem nele ocupa (HEIDEGGER, 1991, p. 72-73).

\section{Gilbert Simondon}

Assim como em Heidegger, o entendimento ontológico do filósofo francês Gilbert Simondon sobre a técnica não se tornou uma mera recusa tecnofóbica dela. Não obstante, Simondon se preocupou em compreender melhor a relação que existe entre o ser humano e os objetos técnicos, interessando-se ao plano em que a nossa cultura técnica pode ser problematizada (dando mais atenção ao caráter objetual da técnica).

Simondon descartou qualquer crítica categórica ou simples otimismo perante a tecnologia. Ora, a questão de nossa relação 'alienante' com a técnica é, na verdade, sempre fruto do mau conhecimento, da falta de consciência e educação tecnológica.

A maior causa da alienação no mundo contemporâneo reside no mau conhecimento da máquina, que não é uma alienação provocada pela máquina, mas por um não-conhecimento de sua natureza e de sua essência, pela sua ausência no mundo de significações, e pela omissão dentro do quadro de valores e conceitos que fazem parte da cultura (...). A cultura é desequilibrada porque ela reconhece certos objetos, como o objeto estético, e Ihes concebe cidadania no mundo de significações, ao mesmo tempo em que reprime outros objetos, e em particular os objetos técnicos, em um mundo sem estrutura, sem um sentido próprio, tendo apenas um uso, uma função útil (SIMONDON, 1969, p.9-10) ${ }^{9}$.

A aprimorada argumentação de Simondon quanto à relação da técnica com o homem encontra igualmente paralelo com Heidegger. No entanto, em Heidegger, se a problematização nietzschiana aparece com toda força - uma vez que o modo de apresentação da técnica moderna é satisfeito por uma metafísica niilista em que 'o ser subtrai-se no mesmo 
processo que se desoculta tecnicamente', ou seja, o problema está na racionalidade humana incapaz de olhar para os maquinismos, para a industrialização da vida e para a 'armação' técnica que faz com que o homem se torne uma disponibilidade -; em Simondon, tão logo, a problematização está no tipo de relação social constituída entre homem e a técnica ao nível da cultura. Se o homem (o zoon technikon) levasse em conta a 'fenomenologia das máquinas', ele teria condições de viver em harmonia na cultura técnica, na medida em que o progresso técnico e progresso humano carecem de estar no mesmo ritmo.

Na visão simondiana, comenta ANDRADE (2008), "não adianta haver uma transformação técnica explosiva se as sociedades não são capazes, na mesma velocidade, de criar um ambiente de entorno propício". Contudo, Simondon é otimista e argumenta que, mesmo com o cenário de acelerações de 'concretização dos objetos técnicos', é preciso apostar no aclopamento harmônico e no aperfeiçoamento do conjunto homem, técnica e natureza.

Para entender melhor a visão deste autor, precisamos mostrar como ele justificou o modo de existência própria da técnica. Isto nos leva a perguntar: o que vem a ser a noção de concretização dos objetos técnicos?

Nos estudos de mecanologia de Simondon, o caráter objetual da técnica está na noção de concretização: noção central para apreender o modo de existência dos objetos técnicos.

Temos, por base, formar uma ontologia genética no pensamento simondiano. A finalidade da tecnogênese é a concretização. A tecnogênese se divide em duas etapas essenciais. Na primeira etapa da evolução técnica, os objetos técnicos são considerados abstratos (ou artificiais), isto é, não ganharam independência e coesão, ao ponto de ainda precisarem do elemento humano para o seu funcionamento (pois são 'a tradução intelectual do homem'). Ao se tornarem concretos (segunda etapa), os objetos técnicos ganham existência própria no mundo, uma vez que avançam na independência e coesão, garantem uma integração convergente de funções e uma sobredeterminação funcional.

Para formular estas ideias, Simondon estudou a evolução dos motores a combustão. Diferentes dos abstratos, os objetos técnicos concretos (as máquinas, por excelência) compõem-se de uma agregação de diversos elementos e funções. No caso do motor à combustão, temos: a vela, distribuidor, carburador, filtro de óleo, volante, pistão etc. O ambiente sistêmico destes objetos forma a coerência interna que transforma a energia química em energia mecânica por meio de ciclos termodinâmicos: o motor à combustão.

Ao se tornar mais evoluído, o objeto técnico passa a ser mais indivisível e multifuncional. A concretização dos objetos técnicos é uma forma de autonomização. No entanto, a técnica nunca se torna uma autonomia absoluta (a ideia de um robô, é sempre uma ideia, um objeto técnico abstrato). Assim, apesar de o objeto técnico tender a se assemelhar com o objeto natural, isto nunca é satisfeito. Há sempre uma margem de indeterminação, um horizonte em aberto, para o processo de evolução dos objetos. Simondon nos fala do equilíbrio metastático que acompanha a evolução dos objetos. Isto garante aos objetos se agregarem 
sistematicamente com outros conjuntos técnicos, criando um ambiente sinérgico e aberto ${ }^{10}$.

Como interpreta Stiegler (1993), a discussão simondiana da evolução técnica situa-se no próprio objeto técnico e não no homem. Na concretização dos objetos não é preciso incluir determinações sociais, econômicas, históricas. A máquina se concretiza no mundo para obter um resultado. Ela é uma objetivação cultural. No objeto técnico industrial, a intencionalidade própria da máquina modifica o ambiente do homem no mundo. Como o próprio Simondon escreve:

O homem, intérprete das máquinas, é também aquele que, a partir de seus esquemas, fundou as formas rígidas que permitem a máquina funcionar. A máquina é um gesto depositado, fixado, tornando-se esteriopadas e com poder de repetição (SIMONDON, 1969, p. 138).

Ora, Simondon nota o imenso plano de hibridez homem-máquina que é preciso ininterruptamente ponderar. Ele rejeita, pois, qualquer visão de substancialismo ou hilemorfismo $^{11}$. Não se deve separar a energia da matéria da energia do humano. E não é correto pensar que haja uma superioridade humana na relação com os objetos técnicos (ou vice-versa). Ambos constituem um universo de causalidade recíproca ${ }^{12}$. Deve-se cobrar, enfim, uma reflexão que explora as trocas de energias e relações físicas e coletivas entre os seres técnicos, humanos e inanimados.

As instâncias que demarcam a 'separação e união' entre os seres técnicos, humanos e inanimados são as noções de individuação ${ }^{13}$ e meio associado. A individuação técnica (ontogênese) torna possível captar como os objetos técnicos estão em permanente processo de instauração de uma realidade relativa, acompanhada por diferentes processos de transduções ${ }^{14}$ e mediações de forma, matéria e energia formando um conjunto articulado: um meio associado.

O ambiente e os objetos técnicos se encontram em um meio associado, afiançando um relacionamento entre suas existências e evoluções. De tal modo, a individuação não somente configura um argumento ontológico-existencial: o indivíduo não está isolado nele mesmo, pois também se encontra em um meio associado - em um sistema - que compreende o meio natural e técnico, formando o entorno de um objeto e forçando a contínua individuação da técnica e do homem ${ }^{15}$.

No nível filosófico, os objetos técnicos não estão em uma oposição direta com os homens. No entanto, os objetos técnicos se transformam em algo problemático tão logo que se problematizam ao nível da cultura (isto é, das crenças, comportamentos, instituições etc. No ambiente industrial da modernidade, pensou Simondon, é preciso na verdade 'salvar o objeto técnico' (SIMONDON, 1983), na medida em que a automação tecnológica como uma necessidade externa, estritamente econômica - somente pensa nos padrões de eficácia capitalista, não respeitando as invenções e evolução próprias à existência dos objetos técnicos e sua mediação com o homem.

Simondon e Heidegger, mesmo partindo de uma mesma reflexão ontológica sobre a técnica, se distinguem no que diz respeito às suas 
conclusões. Quanto a isso, ASPE (2002, p.16) escreve que "há, sem dúvida, uma proximidade real com Heidegger, relativa à natureza do pensamento filosófico, mais precisamente, à não-exterioridade de quem pensa o pensamento que o atravessa. Mas essa proximidade não funda uma interpretação do pensamento de individuação sobre a base da 'diferença ontológica' [de Heidegger]" 16

Tal como interpretamos, Heidegger, buscando uma filosofia essencial, originária, de procura pelo 'sentido do Ser', não certificaria a perspectiva simondiana de procura pelo 'sentido do Devir'. Ora, a teoria da individuação, como atesta suas obras posteriores, é a grande e original preocupação de Simondon e é neste ponto que ele se distingue de Heidegger, pois, "não podemos, no sentido usual do termo, conhecer a individuação, só podemos individualizar, nos individualizar e individualizar em nós mesmos, (...) é pela individualização do conhecimento e não pelo conhecimento sozinho que a individuação dos seres não objetos é apreendida" (SIMONDON, 1989 apud ASPE, 2002, p.16) ${ }^{17}$.

Para Simondon, é preciso pensar a tecnicidade como a resolução de um habitat que agrega as potencialidades das transduções - do devir, do vir a ser - tanto dos objetos técnicos (o seu grau de concretização) como do seu entorno. O meio técnico cria um meio geográfico, e cabe ao homem entender sua dimensão e se preocupar com a cultura técnica (que não é sinônimo simplesmente de tecnicismo, tecnocracia) ${ }^{18}$ que é própria em sua vida.

Conforme a leitura crítica de Stiegler (1993), Simondon deixou todas as condições para se pensar o modo em que a individuação do homem e da técnica (e da dimensão temporal que acompanha o devir, transformações, mutações desses seres) é salientada pelo problemático contraste entre a alta saturação da individuação técnica e a 'defasagem' da individuação psíquica e coletiva. No dizer de Stiegler:

\begin{abstract}
Este 'avanço' das identidades técnico-objetivas sobre a identidade psico-social não é considerada por Simondon. Ela corresponde àquilo que Leroi-Gourhan e [Bertrand] Gille analisam cada um a sua maneira, como um avanço da técnica sobre a sociedade. Na tensão entre o já e o ainda-não é que se crê assim constituir o êxtase temporal maleável entre o passado, o presente e o futuro, onde o indivíduo permanece sempre a alcançar.
\end{abstract}

$\mathrm{Na}$ filosofia simondiana, o esgotamento do tipo de relacionamento entre o homem e a técnica na modernidade perfaz a ideia de um ambiente de metaestabilidade em que a individuação psico-social, ainda não constituída na modernidade, tem de enfrentar a identidade individual dos objetos técnicos e de todos os artíficios em alto estágio de constituição.

Em Simondon, contudo, a relação entre a técnica e o homem é percebida pelo horizonte de hibridez homem-máquina. Esse filósofo percebeu o quanto a evolução e concretização dos objetos técnicos desprovêem a ideia de uma oposição entre a cultura e técnica. Assim, na modernidade, a relação impõe o estabelecimento de um verdadeiro humanismo técnico; no qual as sociedades como um todo sejam capazes de se inserir em processos sociais e educativos que envolvem um 
entendimento mais consciente e harmônico com o universo tecnológico que faz parte dela.

\section{Considerações Finais}

Desde Nietszche, houve um alerta sobre a crise da modernidade perante o progresso técnico. Ele nos ponderava sobre o foco estreito e limitado do modo de representar do homem moderno, que busca apenas a apropriação e objetivação técnico-científica da natureza e do humano. A figura do homem moderno se tornava o da felicidade como banalização dos prazeres, superabundância e de 'possuir o mundo' e 'preencher o tempo' 19.

Heidegger se encontra nesta esteira de interpretação nietzschiana do papel da técnica moderna na modernidade ${ }^{20}$. Para ele, o sentido crítico da modernidade se expressa na imperativa obstinação e uniformidade encampada pela volição da técnica moderna. Como vimos, a relação técnica e homem é evidenciada pelo ser da técnica na modernidade: o Gestell. É por meio dele que se organiza o explorar, o transformar, o estocar, o distribuir, o consumir em um total círculo vicioso que absorve o ser do homem. O homem, não compreendendo como seu próprio ser está tomado pelo ser da técnica na modernidade, fica imerso no perigo do caráter ontológico-histórico deste último.

Como vimos, não é propriamente o conceito da técnica em si, retomado desde a Grécia Antiga, que o filósofo veio questionar, mas sim o modo problemático de um pensamento reflexivo obliterado pela modernidade e não incorporado na técnica moderna. Ora, o perigo do Gestell é tornar-se totalmente absorvido em si mesmo, como uma vontade impessoal, evidenciando-se apenas uma disponibilidade, um reservatório de energia, em que o homem é envolvido, mesmo pensando ser o 'senhor da natureza'.

Simondon, ao pensar mais contigencialmente a ontologia, distinguese da perspectiva mais originária e substancial de Heidegger. A partir de sua procura pelo 'sentido do devir', ele também estaria sob o legado nietzschiano, quando se aproxima da perspectiva contingencial do humano, levando-o a pensar a individuação.

No entanto, na sua problematização da relação entre a técnica e o homem, conjetura-se, em primeiro lugar, que os seres técnicos formam um meio associado (milleu associé) e realizam uma viva interação com os outros seres (humanos e inanimados), por uma tecnicidade e um meio geográfico próprio que expressam essa interação e perfazem um horizonte para individuação humana.

Através de estudos da evolução das máquinas, Simondon pôde apresentar os processos que definem a diferenciação 'incerta' e 'imponderável' dos objetos técnicos, que é autônoma à vontade dos produtores e pode, como vimos, destacar-se por seu horizonte avançado de evolução, que o homem não compreende e isto tornar-se problema ao nível da cultura ${ }^{21}$.

Enquanto a meditação de Heidegger recai na busca do horizonte fenomenológico e historial que 'cindiu' a essência da técnica moderna com 
a essência do homem; a epistemologia de Simondon recai na busca do horizonte fenomenológico de imbricação e devir homem-máquina. Ainda, em Heidegger, o ser do homem no mundo se encontra na originalidade do Dasein - do ser-aí, que supõe uma fenomenologia para explicar a potencialidade, transcendência e liberdade do ser dentro de um determinado desenvolvimento histórico das tecnologias; em Simondon há uma forte diluição da noção de originalidade do humano em favor da noção de individuação dentro de uma ontologia de cunho genético.

Ora, a meditação não-antropológica da técnica de Heidegger se reporta a uma forte crítica do próprio sentido tradicional de humanismo - o caráter de volição 'destinal' da técnica moderna é uma dos fundamentos metafísicos de nossa época, que consuma uma reflexão sobre a essência do ente e uma decisão sobre a essência da verdade ${ }^{22}$. Por sua vez, a epistemologia de Simondon, embora mostre a 'crise dos sentidos' no humanismo (pois o humanismo clássico não entende a realidade humana nos objetos técnicos), procura instituir, de toda forma, uma nova veste ao próprio humanismo, um humanismo técnico, por assim dizer, que aprecie e harmonize o mútuo agenciamento homem-técnica, pois no fim das contas o homem precisa governar.

O pensar ontológico genético de Simondon é um convite para refletir que a formação do ser da técnica e do ser humano nunca é una, mas desuna. Na hibridez homem-máquina, tanto a técnica é instância do humano como o humano é instância da técnica. Isto marca a originalidade de Simondon, pois foge de qualquer pensar objetivante. $E$ isto deve ser reconhecido ao nível da cultura. Os objetos técnicos devem ser humanizados, a ponto em que haja um nexo entre a evolução da concretização da técnica e a cultura contemporânea, como um verdadeiro humanismo técnico. A cultura técnica deve ser sinônimo de humanismo e não de tecnicismo.

Com estas resoluções sobre a cultura técnica (e ainda que sem intenção programática explícita), Simondon foi uns dos pioneiros em argumentar e enriquecer o tema do pós-humanismo e da crítica aos dualismos - mente e corpo, sujeito e objeto, orgânico e inorgânico, social e técnico etc. -, que é corrente hoje em pensamento como o de Bruno Latour. Como vimos, foi mesmo afastada a reivindicação de uma 'natureza humana' que seja hilemórfica e substancial. Ora, a ontologia genética de Simondon tem esta concordância: eleva a visão de alteridade, sendo contra a separação e dicotomia entre as instâncias do homem, técnica e natureza.

Por sua vez, Heidegger, na relação ser do homem com o ser da técnica moderna, há a introdução de um questionamento que faz pensar o humanismo de uma forma mais radical. Para ele, o humanismo, tal como é circunscrito na história ocidental, satisfaz um homem incapaz de sair da racionalidade antropológica (que, em certa medida, Simondon acabaria ficaria 'preso'), de apenas envolvimento com o 'legado cultural' e abandono da busca pela essência do ser humano. Na modernidade, a posição antropológica faz esquecer que, antes de ser 'senhor da natureza', o homem (e a natureza) estão na disponibilidade total do Gestell.

É bastante evidente que a posição radical de Heidegger não se satisfaz com o mero questionamento de decisões culturais. Isso talvez 
divida bastante as conclusões e interpretações que evocam filiações acadêmicas em Heidegger ou Simondon. Não será ao nível de instâncias, de instituições políticas que o homem mudará seu engajamento no mundo e se salvará; mas por meio de uma 'escuta do ser', do nascimento de um novo pensamento, de um novo pensar, que vai além da racionalidade técnico-científica. O humanismo deve, pois, dar atenção para a humanitas do homo humanus; buscando a linguagem originária que ultrapasse a linguagem técnico-científica e dê a devida atenção à abertura ontológicahistorial do Ser (HEIDEGGER, 1991; DUARTE, 2006).

\section{Nota}

${ }^{1}$ Indicamos dois textos bastante esclarecedores: "O que existe de propriamente escandaloso na filosofia da técnica de Heidegger" (MAUER, 2000) e "Heidegger como crítico da modernidade" (BRÜSEKE, 2001).

${ }^{2}$ Como interpreta VATTIMO (1995, p. 30): "Analizando con atención el fenómeno del mundo se descubre que 'el 'mundo' no es en modo alguno una determinación del ente opuesto al Dasein, sino que por el contrarió es un carácter del Dasein mismo'”.

${ }^{3}$ RÜDIGER (2008, pp. 14-5) sintetiza esta mudança ressaltando alguns elementos históricos e biográficos importantes: "Pondo de lado a reflexão sobre o fazer artesanal com que ele se ocupa em Ser e tempo (1927), a reflexão heideggeriana sobre a técnica se desenvolve com a chamada virada de seu pensamento, ocorrida durante os anos de ascensão do regime nazista, sobretudo entre fins de 1934 e 1938. Nesta época, o filósofo começa a retomar as fontes espirituais do Ocidente, visando revelar o que havia sido por ele esquecido e silenciado. Heidegger supunha que, do amálgama do nosso legado espiritual com a técnica mais avançada, poderia surgir, ao menos filosoficamente, a superação da metafísica do sujeito e da própria era moderna e seus desvarios. Talvez seja assim que possa ser salva sua alusão, aparentemente acrescentada ao manuscrito original, à "verdade e grandeza do movimento nacional-socialista", feita em Introdução à Metafísica".

${ }^{4}$ Brüseke (2001) nos traz uma análise apurada do processo de desocultamento técnico na obra de Heidegger, salientando o sentido de termos como: homogeneização; funcionalização; desocultação; polarização entre o sujeito e objeto; o cálculo; vontade, imposição, dominação; fabricar e manusear; consumo e substituição; entre outros.

5 Segundo VATTIMO (1996, p.35), "(...) [n]a análise heideggeriana do nexo entre metafísica, humanismo e técnica, o sujeito era, precisamente ele, a raiz dessa desumanização, já que a subjetividade que se define doravante apenas como o sujeito do objeto é pura função do mundo da objetividade, tendendo, ao contrário, irrefreavelmente, a também se tornar objeto de manipulação".

${ }^{6} \mathrm{Na}$ terminologia heideggeriana, o termo Gestell é um dos mais intraduzíveis. Na literatura, inúmeras tentativas foram realizadas: "dispositivo" (Duarte, 2006), "armação" (Loparic, 2002), "composição" e "disposição" (Carneiro Leão, in: Heidegger, 2001), citando apenas as que apropriamos neste artigo. BRÜSEKE (2001) nota ainda que o verbo Stell (que significa comumente "pôr", "colocar", nos sentidos de "impor" e "demandar") possibilita a formação de uma nuvem de conceitos (Begriffswolke) em Ge-stell, "além do mais, é de certa maneira a essência do desocultamento técnico, então de todas as atividades modernas, que deixam se caracterizar como stellen, i.e. como certo acesso ao Ser, que demanda e desafia o mesmo, na homogeneização, materialização e funcionalização. No ato da imposição (Durchsetzen) da demanda (das Stellen) desoculta (entbirgt) a técnica moderna o Ser, todavia de uma maneira que impossibilita a sua revelação (Offenbarkeit) plena"

7 "De novo, se impõe a pergunta: será que este desencobrir se dá, em algum lugar, fora de toda ação e qualquer atividade humana? De forma alguma! Mas também não acontece apenas no homem e nem decisivamente pelo homem”. “(...) Quando o des-coberto já não atinge o homem, como objeto, mas exclusivamente, como disponibilidade, quando, no domínio do nãoobjeto, o homem se reduz apenas a dis-por da disponibilidade - então é que chegou à última beira do precipício, lá onde ele mesmo só se toma por dis-ponibilidade" (Idem, p. 26-7; 29).

${ }^{8} \mathrm{Na}$ belíssima passagem que fecha sua meditação sobre a técnica, Heidegger lembra que o perigo carrega consigo aquilo que salva: "Quando mais nos avizinharmos do perigo, com maior 
clareza começarão a brilhar os caminhos para o que salva, tanto mais questões haveremos de questionar. Pois questionar é a piedade do pensamento" (p. 38).

9 Todas as citações de Simondon no corpo do texto são traduções livres nossas.

10 "La concrétisation donne à l'objet technique une place intermédiaire entre l'objet naturel et la représentation scientifique. L'objet technique abstrait, c'est-à-dire primitif, est très loin de constituer un système naturel (...). Au contraire, l'objet technique concret, c'est-à-dire evolué, se rapproche du mode d'existence des objets naturels, il tend vers la cohérence interne, vers la fermeture du système des causes et des effets qui s'exercent circulairement à l'intérieur de son enceinte (...). Cet objet, en évoluant, perd son caractère d'artificialité (...)" (SIMONDON, 1969, p.46).

${ }^{11}$ Por definição, o substancialismo é entendido como a tradição que admite a existência de uma ou mais substâncias como completamente distintas dos fenômenos. O hilemorfismo, como a tradição que determina os seres corpóreos compostos essencialmente de matéria (hyle) e forma (morphe). Segundo a proposição inicial de Aristóteles, o hilemorfismo explica o 'todo natural', uma 'matéria prima' que garante a identidade essencial de uma substância. Portanto, no horizonte de hibridez homem-máquina simondiano, tanto o substancialismo como o hilemorfismo não satisfazem, pois o processo de individuação (e não de individualidade) não encontra expressão.

12 “(...) la condition première d'incorporation des objets techniques à la culture serait que l'homme ne soit ni inférieur ni supérieur aux objets techniques, qu'il puisse les aborder et apprendre à les connaître en entretenant avec eux une relation d'égalité, de reciprocité d'échanges: une rélation sociale en quelque manière" (SIMONDON, 1969, p.88).

${ }^{13} \mathrm{~A}$ individuação será a noção-chave das duas obras mais importantes, posterior a "Du mode de l'existence des objets technique" [1958]: "L'individu et sa genèse physico-biologique" [1964] e "L'individuation psychique et collective" [1989]. O processo de individuação será visto não somente na técnica, mas também nas formas físicas, biológicas e coletivas.

${ }_{14}^{14}$ Transformação de uma energia numa energia de natureza diferente.

15 Sobre isso, HAVELANGE (2005, p.9) faz um comentário interessante: "A l'instar de la philosophie de la vie de Nietzsche, fortement articulée à la physiologie de son temps, la philosophie de Simondon entretient avec les disciplines scientifiques de son époque (physique, biologie, théorie de l'information) des rapports étroits qui dépassent le seul propos de l'épistémologie: les concepts de processus d'individuation (faisant fond sur un potentiel préindividuel, quoique ne l'épuisant jamais) et de relation transductive (productrice de ses propres termes, et non l'inverse) érigent au niveau de l'être (ou, plus exactement, du devenir en tant que dimension intrinsèque de l'être) des relations jusque-là assignées au seul domaine cognitif ou noétique. Cette philosophie offre ainsi un cadre théorétique particulièrement propice à une thématisation de la technique, quoique celle-ci soit loin d'être pleinement effectuée. Elle présente par ailleurs une affinité incontestable avec les développements contemporains de la phénoménologie évoqués plus haut, dans la mesure où ceux-ci remettent en cause l'opposition de l'empirique et du transcendental".

16 "Il y a sans doute ici une proximité réelle avec Heidegger, relative à la nature de la pensée philosophique, plus précisément, à la non-extériorité de celui qui pense à la pensée qui le traverse. Mais cette proximité ne fonde pas une interprétation de la penséé de l'individuation sur la base de la 'différence ontologique'" (no original, tradução nossa).

17 "Nous ne pouvons, au sens habituel du terme, connaître l'individuation; nous pouvons seulement individuer, nous individuer, et individuer en nous ; [...] c'est par l'individuation de la connaissance et non par la connaissance seule que l'individuation des êtres non sujets est saisie. Les êtres peuvent être connus par la connaissance du sujet, mais l'individuation des êtres ne peut être saisise que par l'individuation de la connaissance du sujet"' (no original).

18 "Il est nécessaire que l'objet technique soit connu em lui-même pour que la relation de I'homme à la machine devienne stable et valide: d'où la necessité d'une culture technique" (SIMONDON, 1969, p.82).

${ }^{19}$ Nietzsche pensava que era no modo de representar do 'último homem' (isto é, do homem moderno) que se expressava um horizonte metafísico visando apenas a apropriação técnicocientífica da natureza. Ora, o 'último homem' quer transformar tudo em algo ajustado, preciso, visado. Seu foco é sempre estreito e limitado. E sua objetivação de 'representar' e 'disponibilizar' a totalidade dos entes impede-o de sair de uma vontade máxima, a saber: "transformar a realidade de tudo o que é em objeto do representar e do fazer humanos e, por 
esse meio, torná-la infinitamente operável e manipulável, graças ao recurso da apropriação técnico-científica" (GIACOIA, 1999, p.43).

${ }^{20}$ Ver SILVA (2000).

21 SIMONDON (1969, p. 9) escrevia na abertura de seu livro: "La culture s'est constituée en système de défense contre les techniques; or, cette défense se présente comme une défense de l'homme, supposant que les objets techniques ne contiennent pas de réalité humaine (...). L'opposition dressée entre la culture et la technique, entre l'homme et la machine, est fausse et sans fondement ; elle ne recouvre qu'ignorance ou ressentiment. Elle masque derrière un facile humanisme une riche en efforts humains et en forces naturelles, et qui constitue le monde des objets techniques, médiateurs entre la nature et l'homme".

${ }^{22}$ Heidegger não se submete a um compromisso com o tipo de humanismo de sua época. Sobre isso, convém lembrar sua conferência "A época da imagem do mundo", em que escreve: "Em sentido histórico estrito, o humanismo não é nada além de uma antropologia estéticomoral. O título de antropologia não designa nenhuma pesquisa pertencente às ciências naturais. Também não designa a doutrina estabelecida no contexto da teologia cristã sobre a criação, queda e redenção do homem. Ele assinala a explicação do homem que explica e avalia a totalidade do ente a partir do próprio homem e a ele retorna" (HEIDEGGER, [1938]). 


\section{Referências}

ANDRADE, Thales de. Intersecções entre o ambiente e a realidade técnica: contribuições do pensamento de G. Simondon. In: Revista Ambiente \& Sociedade, n̊8, Campinas, jan-jun, 2001.

ASPE, Bernard. Être singulier commun. In: Chabot, Pascal, Simondon. Vrin, 2002.

BRÜSEKE, Franz Josef \& SELL, Carlos Eduardo. Heidegger, teoria social e modernidade. In: Teoria \& Pesquisa, n. 48, p.11-44, 2006.

BRÜSEKE, Franz Josef. Heidegger como crítico da técnica moderna. In: Brüseke, F.J. A Técnica e os riscos da modernidade. Florianópolis: Editora da UFS, p. 57-114, 2001.

DUARTE, André, Heidegger e Foucault. Críticos da modernidade: humanismo, técnica e biopolítica. In: Revista Trans/Form/Ação, vol. 29, n 2, Marília, 2006.

GIACOIA Jr., Oswaldo. O último homem e a técnica moderna. In: Revista Natureza Humana. v.1, n1, São Paulo, p. 33-54, 1999.

HAVELANGE, Véronique. De l'outil à la médiation constitutive: pour une réévaluation phénoménologique, biologique et anthropologique de la technique. In: Arob@se (www. www.univ-rouen.fr/arobase), vol. 1, p.8-45, 2005.

HEIDEGGER, Martin. "Gelassenheit” [1955]. In: Serenidade, Tradução portuguesa de Maria Madalena Andrade e Olga Santos. Piaget, Lisboa, 2000.

HEIDEGGER, Martin. Carta sobre o humanismo. Trad. Rubens Eduardo Frias, São Paulo, Moraes, 1991.

HEIDEGGER, Martin. Ser e Tempo (parte I). Petrópolis Vozes,, 2005.

HEIDEGGER, Martin. A época das imagens do mundo. Conferência de 9 de junho de 1938. Tradução de Claúdia Druker "Die Zeit des Weltbildes" [1938]. In: Heidegger, Martin. Holzwege. Frankfurt: Vittorio Klostermann, 6a. 1980, pp. 73-110). Disponível em: http://www.cfh.ufsc.br/ wfil/heidegger.htm. Acessado: 12 mai. 2010.

HEIDEGGER, Martin. A questão da técnica. In: Ensaios e conferências. Petrópolis, Vozes, p. 11-38, 2001.

HEIDEGGER, Martin. O fim da filosofia e a tarefa do pensamento. In: Os pensadores. 4. ed. São Paulo: Nova cultural, p.64-81, 1991. 
LOPARIC, Zeljko. Breve nota sobre Heidegger como leitor de Jünger. In: Revista Natureza Humana, v.4, p. 217-220, jun. 2002.

MAUER, Reinhart. O que existe de propriamente escandaloso na filosofia da técnica de Heidegger. In: Revista Natureza Humana. Tradução Osvaldo Giacoia Junior, n.2(2), p. 403-427, 2000.

NEVES, José Pinheiro. Seres humanos e objectos técnicos: a noção de 'concretização' em Gilbert Simondon. In: Revista Comunicação e Sociedade, vol. 12, Minho, 2007.

RÜDIGER, Francisco. Declínio do ocidente, tragédia da cultura e ascensão dos titãs: elementos genealógicos da discussão da técnica em Heidegger. In: Revista Estudos de Sociologia, v.13, n.24, Araraquara, p.13-28, 2008.

SILVA, Juremir Machado da. De Heidegger a Baudrillard: os paradoxos da técnica. In: Revista Famecos, n13, Porto Alegre, dez. 2000.

SIMONDON, Gilbert. 'Sauver l'objet technique'. Entretien avec Gilbert Simondon”. In: Revue Esprit, n73, p. 147-52, 1983.

SIMONDON, Gilbert. Du mode d'existence des objets techniques. Aubier-Montaigne, Paris, 1969.

SIMONDON, Gilbert. L'individuation psychique et collective. Breteuil-surIton, Aubier, 1989.

STIEGLER, Bernard. Temps et individuation technique, psychique, et collective dans l'ouvre de Simondon. In: Multitudes - Futur Antérieur, n99-20, 1993. Disponível em: http://multitudes.sam izdat.net/Temps-etindividuation-technique.html, 1993. Acesso em: 29 nov. 2009.

STIEGLER, Bernard. La technique et le temps. La faute d'Epimethee. Galilee, Paris, 2001. Vol.1.

VATTIMO, Gianni. Introducción a Heidegger. Gedisa, Barcelona, 1995. 